\title{
Does Airport Preferential Policy Aggravate the Competition of Aviation Hubs in Central and Western China? Based on the Investigation of 78 Airports
}

\author{
Chengyu Li iD, ${ }^{1}$ Xiangwu Yan $(1),{ }^{2}$ Yanbing Zhang, ${ }^{2}$ Ning Xu, ${ }^{3}$ Jin Chen, ${ }^{4}$ \\ and Guangliang Zhou ${ }^{5}$ \\ ${ }^{1}$ Industry \& Innovation Research Center, Zhengzhou University of Light Industry, Zhengzhou, China \\ ${ }^{2}$ School of Economics \& Management, Zhengzhou University of Light Industry, Zhengzhou, China \\ ${ }^{3}$ School of Tourism, Xinyang Normal University, Xinyang, China \\ ${ }^{4}$ School of Humanities \& Law, Jiangxi Institute of Economic Administrators, Nanchang, China \\ ${ }^{5}$ Social Science Management Department, Zhengzhou University of Light Industry, Zhengzhou, China
}

Correspondence should be addressed to Xiangwu Yan; xiangwu.yan@zzuli.edu.cn

Received 25 April 2021; Accepted 12 June 2021; Published 21 June 2021

Academic Editor: Lin Zhou

Copyright (C) 2021 Chengyu Li et al. This is an open access article distributed under the Creative Commons Attribution License, which permits unrestricted use, distribution, and reproduction in any medium, provided the original work is properly cited.

\begin{abstract}
China's regional economic competition is intensifying; in particular, the cluster development of air transport, high-end manufacturing, and modern service industries is closely related to the construction of regional airports. Local governments have listed aviation hubs as the hardcore advantage of high-quality growth in the new era, but it may also lead to excessive convergence and preferential system competition. Based on the "GDP competition" of local governments in China, this paper uses panel data of 78 airports in mainland China from 2001 to 2018 and tries to explore the causes of airport preferential policies. The Synthetic Control Method is used to study the influence of preferential policies on airport passenger and cargo flow, and then the Spatial Durbin Model is used to verify the spatial spillover effect of aviation hubs, which may be magnified by the preferential policies. This paper finds that the impact of preferential policies on airports in central and western China is mainly reflected in the increase of cargo throughput, and there is a spatial siphon effect on cargo throughput between airports. The implementation of the preferential policy enhances this spatial siphon effect, which in turn leads to more fierce competition. The research results show that the preferential policies, issued in central and western aviation economy, have shown a trend of evolving in the direction of vicious competition. Before the airport preferential system produces more negative effects, it should be corrected in time, and each aviation economic zone in the central and western regions should be scientifically coordinated and reasonably planned.
\end{abstract}

\section{Introduction}

In recent years, many aviation hub cities in central and western China have put forward plans to speed up the construction of airport economic zones or aviation metropolises, and various governments have issued various preferential policies to support the construction of airports and routes. However, judging from the service scope of the airport economic zone, after the completion of the airport economic zone, there will be certain exclusiveness within the 800 -kilometer area, and the intensive construction of the aviation economic zone in central and western China may lead to the problems of convergence competition and malicious suppression [1].

The construction of airports is usually closely related to the regional economy. Local governments generally attach great importance to investment in local airport infrastructure and adopt preferential policies to speed up the development of the regional airport economy. However, there have always been two opposing views on whether airports and airlines should be subsidized for a long time. Some scholars believe that the long-term subsidy for airports 
violates the principle of fair competition, which will lead to inefficiency of airports under local protection and make the local airport never find its accurate position in the existing large international airport competition, so it will never make a profit $[2,3]$. Some studies have also confirmed that if regional government subsidies are stopped, almost all German airports will not be able to make up for their annual losses [4]. Another point of view is that we should not only pay attention to the direct loss or profit of regional airports while ignoring their promoted effect on the regional economy. The evidence of airport areas, especially airports in the United States, emphasizes the huge positive impact of airport spillover effects on the surrounding economy [5-7]. European Low-Fare Airline Association also pointed out that the rapid development of airports has promoted interregional connectivity, as well as exchanges and prosperity of domestic and international trade [8]. Therefore, although the debate continues, the phenomenon of local government policy support for airport construction is an objective fact, and the economic effect of airport construction is still a hot issue, which needs to be discussed in depth [9].

This paper focuses on whether the preferential behavior of local governments will aggravate the vicious competition of airports in the central and western regions. Therefore, under the background of deepening the market-oriented reform of domestic freight rates of civil aviation, using the panel data of 78 airports in Chinese mainland from 2001 to 2018, we first utilize the Synthetic Control Method (SCM) to study the impact of preferential policies on airport passenger flow and cargo volume. Then, we add spatial related factors to the model to analyze the spatial spillover effect of passenger and cargo flow and then study whether preferential policies will expand this spatial effect. The possible marginal contribution of this paper lies in the following points. First, compared with the existing studies, the capacity of research samples has been greatly expanded, and more consistent and universal conclusions can be drawn. Secondly, through the ranking test, false experiment, and changing spatial matrix, a more robust conclusion is drawn. Thirdly, the SCM is combined with the Spatial Dubin Model (SDM), and the results of the two models confirm each other, which proves that preferential policies will aggravate the siphoning effect of airports, thus leading to more intense and even malicious competition. The conclusion of this paper has important practical significance for rationally planning the aviation economic zone in the central and western regions, exploring the differentiated development, and smoothing the domestic and international double circulation strategy through the aviation industry.

The rest of this paper is arranged as follows. The second part is the literature review. The third part is model setting and data introduction. The fourth part is the empirical study. Firstly, the SCM is used to analyze the impact of preferential policies on aviation economic zones. Then, the spatial spillover effect of the aviation economy is studied by using SDM, and the realization path of preferential policy is studied. The fifth part further discusses the reasons for the emergence of the preferential system. The last part reviews the previous content and puts forward some suggestions on the influence of aviation economic preferential policy.

\section{Literature Review}

2.1. The Historical Origin and Realistic Influence of Preferential Policies. In the past three decades, the promotion tournament between government officials based on GDP growth is an important source of China's rapid economic growth [10]. Under the incentive of a job promotion, local government officials give preferential policies to specific industries with high returns, so that they can quickly gather production factors, develop rapidly, and improve the regional economic level. In a catch-up economy, local governments can learn from the development experience of other countries to identify high-efficiency industries. However, the catch-up characteristics of the current economy are getting weaker and weaker. The innovative economy has become the main force for future development, and the preferential model is increasingly difficult to achieve good effects [11]. Meanwhile, in the initial stage of economic development, when society believes that economic growth is the first goal, the preferential behavior of the government is acceptable. But, as the economy enters a new stage of development, the nature of government decision-making to protect multi-interests becomes more obvious and the cost of "GDP championship" is increasing day by day. Some factors, such as vicious interregional economic competition and distorted allocation of resources, have become increasingly exposed and begun to restrict economic growth [12].

When the economic environment changes, the preferential model may change from a booster to an obstacle to economic development [11]. Some scholars had studied the return on investment of enterprises, which got more government intervention, and concluded that the return on investment of these enterprises is generally lower than that of common enterprises, which are not affected by government intervention $[13,14]$. Particularly, the return on investment of private enterprises is often much higher than that of state-owned enterprises $[15,16]$. The deep-seated reason for the situation is that the distorted incentives of the Chinese government and the imbalance of input-output structure lead to the low proportion of the output value of China's service industry [17], and this unreasonable industrial structure further affects the rate of return on investment $[18,19]$.

From the above analysis, we can find that the implementation of the preferential policy will reduce the rate of return on investment and distort the allocation of resources. For this reason, we put forward the following hypothesis.

$\mathrm{H}_{1}$. the airport preferential policy will intensify the convergence competition of aviation hubs in the central and western regions of China, which will have a negative impact on the economy.

2.2. Reasons Why Airports Are Targeted by Preferential Subsidies. According to the early theory of regional unbalanced development, the geographical concentration of 
economic activities comes from the polarization effect, and the unbalanced distribution of economic activities leads to the unbalanced pattern of regional development. Marshall (1920) used economic externalities to explain the geographical imbalance of economic activities. He noted that economic agglomeration mainly comes from labor market sharing, the scale of intermediate input, and the spillover of knowledge and technology. The development of the aviation economy made it convenient for the labor force, knowledge, and technology to gather in different regions. Cao et al. [20] analyzed the reasons for the formation of the airport economic zone from the perspective of new economic geography, which absorbed the idea of increasing scale returns of the new growth theory, and explored the internal evolutionary process of spatial economic agglomeration based on the assumptions of two departments, two regions, and two elements. They pointed out that airport economic activities are gradually strengthened around the airport, and the development of the airport economy will give feedback to the airport. Under the influence of these factors, the airport becomes the core, and other areas gradually become the periphery, which forms the airport economic zone.

The kind of literature closest to the study is the research on Mixed Oligopoly Model. Early research focused on the impact of competition on social welfare, which happened between state-owned and private enterprises in a closed market or region [21-23]. To safeguard the interests of local enterprises, the government has formulated trade protection policies. Although there are different forms of trade protection, its goal is to reduce the prices of local enterprises and make the prices of nonlocal enterprises relatively higher, thus losing their competitiveness. In central and western China, where traffic is underdeveloped, air transport investment is effective quickly, which can quickly reduce transportation costs on products with high added value and lightweight and accelerate the formation of a center-periphery pattern. So, the local governments have listed aviation hubs as the hardcore advantages of high-quality growth and subsidy objects.

From the above analysis, the reason for the government to implement the preferential policy is to enhance the competitiveness of local airports and then seize more markets. To this end, we propose the following hypothesis

$\mathrm{H}_{2}$. the airport preferential policy will increase the passenger or cargo throughput of the local airport.

2.3. Spatial Economic Relations of Airports. In the past, scholars are interested in the impact of the aviation economy on employment [24,25], population [26], and industry [27, 28]. The aviation economy can accelerate the flow of population and labor capital between regions, improve the local employment situation, and finally promote the upgrading of industrial structure and regional economic transformation. Furthermore, some scholars focused on the causal relationship between airports and regional economic development. Granger test is a common method $[1,29]$. However, the test results vary with the change of the test object, so this kind of research does not have universal significance.
With the progress of the theory of new economic geography and spatial econometrics, scholars gradually pay attention to the impact of spatial factors on the airport economy [30]. Generally speaking, the spillover effect of the airport on the regional economy varies with the scale and development stage of the airport [31,32]. In terms of spatial distribution, the spillover effect of airports in eastern China is much higher than that in the west [33]. In the research on passenger volume and cargo volume, Chen et al. [34] carried out the research from the perspective of airline network and found that passenger volume has a significant positive network spillover effect on the regional economy, the spillover effect is far greater than the direct effect on the area, and freight volume only has a positive impact on the local area.

From the above discussion, most scholars have affirmed the positive impact of the aviation economic zone on the region, and some scholars have drawn some conclusions in the test of subregional and subtransport indicators. However, compared with these literature studies, the research object of this paper is richer and the sample period is longer, which ensures that this paper can draw more consistent and scientific conclusions. To sum up, we propose the following hypothesis.

$\mathrm{H}_{3}$. the spatial spillover effect of passenger or freight volume of the airport is negative, which shows the siphoning effect in space.

\section{Model Setting}

3.1. Synthetic Control Method. The Synthetic Control Method (SCM), proposed by Abadie and Gardeazabal [35], gives weight to different control groups, respectively. Based on these weights, the counterfactual control group of policy intervention individuals is constructed and used to simulate the characteristics of the treatment group before being affected by the policy. The actual value of the treatment group is compared with the composite value, to get the policy treatment effect. SCM uses a data-driven method to give weight to synthetic individuals and calculates the contribution of each synthetic individual to the counterfactual control group, which effectively overcomes the subjective and endogenous problems of sample selection and makes up for the limitations of the Difference in Difference method in policy evaluation. We will use this method to test the effectiveness of the preferential policy.

Since most of the airports in eastern China have been mature and SCM is not suitable for the study of large samples, the research object selected by SCM in this paper is the airports of the provinces and cities in the central and western. The basis of regional division comes from China Statistical Yearbook (2019). According to the documents released by the regional governments of the central and western, in 2012, Henan Province took the lead in issuing Some Policies to Support the Development of the Aviation Logistics Industry in Henan Province and Preferential Policies for Henan Province to Support Zhengzhou Xinzheng International Airport to Introduce Base Airlines. To speed up the construction of Zhengzhou Airport, Henan Province not 
only actively strived for preferential policies from the central government but also formulated 20 additional preferential policies, which gave preferential treatment in the aspects of flight subsidy, route development reward, site rental fee reduction, and subsidy, land use, financing, talent introduction, and so on. Therefore, Xinzheng Airport in Zhengzhou becomes the experimental object of this paper. At this time, other airports in the central and western were not affected by the preferential policy or the degree of influence was not as high as Zhengzhou, so they naturally become the control group.

3.2. Spatial Econometric Model. The setting of the spatial weight matrix is the premise and basis of spatial econometric analysis. Because the airport is a point distribution, it is an appropriate choice to use a distance-based spatial weight matrix, but it has the problem of splitting or weakening the relationship between nonneighbors. For this reason, we draw lessons from the treatment methods of Zhang et al. [36] and Gao [37] and construct a weight matrix based on economic-geographical distance. The expression is as follows

$$
M=\frac{1}{d_{i j}} * \frac{1}{\left|\bar{Y}_{i}-\bar{Y}_{j}\right|},
$$

where $Y_{i}$ is the average real GDP per capita of the city where the airport $i$ located and $d_{i j}$ is the large circle distance between the two airports.

Furthermore, the Global Moran's $I$ is used to test and study the spatial correlation of airports. The test results show that each variable, including regional economic, airport passenger throughput, and airport cargo throughput, is significantly greater than 0 at $1 \%$ confidence level. Therefore, the objects studied in this paper have a strong spatial correlation, which indicates that spatial econometric analysis can be carried out.

The data, used in the spatial econometric analysis of this paper, are the data of 78 airports of the Chinese mainland from 2001 to 2018. While paying attention to the spatial autocorrelation of the whole sample airport in China, we divide the samples into eastern, central, and western for testing; the classification basis is consistent with the previous discussion. Referring to the research experience of aviation economy by Wang [32] and Chen et al. [34], in the process of selecting the model, we start from the SDM and then use Lagrange Multiplier Test and Wald Test to analyze whether the SDM can be transformed into Spatial Autocorrelation Model (SAR) or Spatial Error Model (SEM). The test results all reject the null hypothesis, which shows that the SDM is suitable for this study. Furthermore, Hausman test results show that the fixed-effects model is more appropriate than the random effects. Finally, we choose the SDM with fixed effects for research. The model is as follows

$$
y_{\mathrm{it}}=\rho W_{i}^{\prime} y_{\mathrm{it}}+X_{\mathrm{it}} \beta+\theta W_{i}^{\prime} X_{\mathrm{it}}+\mu_{i}+\varepsilon_{\mathrm{it}},
$$

where $y$ is the dependent variable of the model, $X$ is the core explanatory variable and various control variables, $W$ is the spatial weight matrix, $\mu, \theta, \rho$, and $\beta$ are the parameters to be estimated, and $\varepsilon$ is the error term.

3.3. Variable Selection and Data Description. Wang [32] and Chen et al. [34] collected data from 45 airports in China and researched their space spillover effect. Based on the research, this paper expands the sample and selects the balanced panel data of 78 airports in China from 2001 to 2018. The data selected in this paper are mainly from Civil Aviation from the Perspective of Statistics (2001-2018), China Urban Statistical Yearbook (2002-2019), and the annual Statistical Bulletin of Civil Aviation Airport Production. Some of the missing values are made up by consulting the National Economic Development Bulletin and the website of the Bureau of Statistics.

3.3.1. Airport Development Indicators. Airport cargo traffic $(\mathrm{lncm})$ and passenger flow (lntra) are the most intuitive and important indicators to measure the development level of the airport economy [38, 39]. For the case that a city has two airports, according to the experience of other scholars, the passenger and cargo throughput of the airport is combined.

3.3.2. Control Variables. Government intervention (gov). the degree of market competition depends on the degree of government intervention [40]; under the fiscal decentralization system, the GDP tournament between regional governments and the competitive game of officials leads to incentives for the government to directly intervene in local economic activities. Particularly, since the airport ownership reform began in 2001, regional governments have regarded the aviation economy as a new economic growth pole and are more likely to carry out preferential policies. To measure the degree of government intervention, Fan and Zhang [41] used the ratio of regional government expenditure to GDP. However, the researches on the aviation economy [42, 43], which are similar to the content of this article, used the ratio of fiscal government expenditure to fiscal revenue, to reflect the degree of government intervention. The approach is adopted in this paper.

The stock of airport facilities (lnrf) is expressed by the number of takeoffs and landings of aircraft. There are two main ideas in the selection of representative variables of airport infrastructure qualification. First, according to the neoclassical concept of capital, it can be reflected in monetary form, which is mostly used in the existing literature. Second, it can be reflected in the kind form. Percoco [44] used the physical form of the number of takeoffs and landings to measure the airport qualification. Li [33] proved the necessity of using this measure; first of all, the airport has externalities, and its investment decision is not merely based on profit maximization but also based on social benefits. Secondly, the main economic source of airport investment is a central investment, so it is difficult to obtain statistical data and measure it in a unified monetary form. Finally, the construction period of the airport is long, which usually takes $2-3$ years, and inaccurate results may be obtained by 
measuring it in the form of currency. Therefore, to measure the qualification of airport facilities, it is an appropriate way to use the index of the number of takeoffs and landings at the airport.

Regional economic status (lngdp) is expressed by regional GDP, which has been reduced based on 2001. In the case that the radiation scope of the airport economic zone is fuzzy, it is a feasible and common method to use the GDP of the city where the airport is located, to represent the hinterland development level of the airport. Population indicator (lnpop) is expressed by the year-end population. Human capital (lntea) is generally represented by the number of college students. Based on the availability of data, this paper uses the number of full-time teachers in colleges instead. Tourist attraction (lnta) is represented by the number of lodging meal business employees. The research studies of Yang et al. [27] and David and Saporito [28] proved that tourism and aviation economy are closely linked. The industrial structure $(\mathrm{sec})$ is expressed as the ratio of the added value of the secondary industry to regional GDP. Employment in the secondary industry (esis) is expressed by the proportion of manufacturing industry employees and the year-end population. Population density (pd) is expressed by the proportion of the number of people at the end of the year to the area of administrative area. This indicator can be used to reflect the degree of economic prosperity in the hinterland of the airport. Per capita urban road area (proad) is expressed by the proportion of the urban road area to the number of people at the end of the year, which can reflect the convenience of regional transportation. Table 1is the main index and calculation method of data; Table 2is the descriptive statistics of the main indicators in this paper. It should be noted that SCM only selected airports in the central and western as the research objects.

\section{Empirical Results and Discussion}

4.1. Empirical Analysis of the Effect of Preferential Policy. By the data-driven method, SCM obtains the weight of the control group, which can minimize the mean square error (the root mean square prediction error, RMSPE) of the experimental subjects and the synthetic control group before the implementation of the preferential policy. The fitting results of predictive control variables are shown in Table 3.

The passenger and cargo throughput of the Xinzheng Airport in Zhengzhou shown in Table 3is similar to that of synthetic areas. The RMSPE of freight volume and passenger flow is less than 0.1 , and the predictive control variables, such as lngdp, gov, lnpop, and sec, are very close to the real level. The airport development index of the synthetic area, in 2001 and 2006, is highly similar to that of the experimental area, which can prove that the fitting effect of the SCM method is appropriate.

The weights of the synthesized areas are listed in Table 4. According to the cargo traffic of Zhengzhou Airport, the synthetic areas include Nanchang (0.287), Chengdu (0.562), Luoyang (0.057), and Ganzhou (0.095), which indicates that Zhengzhou is the closest to Chengdu in the level of cargo traffic. As for the passenger flow of Zhengzhou Airport, the synthetic areas are Nanchang (0.032), Harbin (Harbin), Wuhan (0.158), Luoyang (0.082), and Changsha (0.543), indicating that the passenger throughput of Changsha Airport is close to that of Zhengzhou.

Then the SCM is carried out, and the estimated results are shown in Figure 1. It is shown that, before the implementation of the preferential policy, the passenger and cargo throughput of the experimental airport and the synthetic airport had a good fit, and after the implementation of preferential policy, the passenger and cargo throughput of Xinzheng Airport showed an increasing trend. Among them, it can be observed that there is a difference in the observed values between the experimental object and the synthetic object before the implementation of the policy, which may be the advanced effect of the policy. Before the Zhengzhou government officially announced the preferential policy, some enterprises had got the news and quickly signed cooperation projects. However, compared with the freight volume, the change of passenger throughput is relatively not obvious, which may due to the orders of goods transportation mainly come from enterprises, and the passenger flow is more spontaneous, which confirms the advance effect of this policy on a certain extent.

4.1.1. Effectiveness Analysis. According to the content, the passenger and cargo transport throughput of the experimental and synthetic subjects is different after the implementation of the policy, but the influence of other factors may not be ruled out. To eliminate the interference of other policy factors and contingency, the ranking test method is adopted. It is mainly used to analyze the robustness of the counterevent experiment, its principle is assuming that the control group airports implement preferential policies, respectively, and in 2012, we applied the SCM to construct the synthetic objects and then compared them with the actual development indicators of each airport. If there is a significant difference in the degree of standard change, measured by the difference between the actual observed value of the experimental object and the observed value of the synthetic object, the policy effect difference between the two is large, and the preferential policy can significantly affect the experimental area. On the contrary, further research is needed.

In this paper, the ranking test is carried out on 37 control group samples outside Xinzheng Airport. However, if the RMSPE of the experimental object is large, which shows that the appropriate weight cannot be found to fit the observed values of the control object, the hypothesis of the SCM is not satisfied. Referring to the practice of Abadie et al. [45], we excluded the airport with RMSPE five times larger than the experimental object in the control group and finally got 25 samples and 32 samples on the cargo and passenger throughput indicators, respectively. In Figure 2, line charts of the standard changes of the experimental subjects, the cargo and passenger throughput of Xinzheng Airport, and the standard changes of other airports are drawn.

As shown in Figure 2, before the implementation of the preferential policy, the difference in cargo traffic volume 
TABLE 1: The main indicators and calculation methods.

\begin{tabular}{|c|c|c|c|}
\hline Variable type & Variable name & $\begin{array}{l}\text { Variable } \\
\text { symbol }\end{array}$ & Variable definition \\
\hline $\begin{array}{l}\text { Dependent } \\
\text { variables }\end{array}$ & $\begin{array}{l}\text { Airport cargo traffic } \\
\text { Airport passenger flow } \\
\text { Economic level } \\
\text { Industrial structure }\end{array}$ & $\begin{array}{l}\operatorname{lncm} \\
\ln t r a \\
\operatorname{lngdp} \\
\text { sec }\end{array}$ & $\begin{array}{l}\text { The logarithm of airport cargo throughput } \\
\text { The logarithm of airport passenger throughput } \\
\text { The logarithm of actual regional gross domestic product } \\
\text { Added value of manufacturing industry/regional GDP }\end{array}$ \\
\hline Control variables & $\begin{array}{c}\text { Population } \\
\text { Facilities qualification of airports } \\
\text { Population density } \\
\text { Tourism attraction ability } \\
\text { Per capita urban road area } \\
\text { Human capital } \\
\text { Employment situation of } \\
\text { secondary industry } \\
\text { Government intervention }\end{array}$ & $\begin{array}{l}\text { lnpop } \\
\text { lnrf } \\
\text { pd } \\
\text { lnta } \\
\text { proad } \\
\text { lntea } \\
\text { esis } \\
\text { gov }\end{array}$ & $\begin{array}{c}\text { The logarithm of the population at the end of the year } \\
\text { The logarithm of the number of airport takeoffs and landings } \\
\text { Population/administrative area } \\
\text { The logarithm of the number of people employed in the } \\
\text { accommodation and catering business } \\
\text { Urban road area/population } \\
\text { The logarithm of the number of full-time teachers in colleges } \\
\text { The number of employed people in the manufacturing industry/ } \\
\text { population } \\
\text { Government budget expenditure/government budget revenue }\end{array}$ \\
\hline
\end{tabular}

TABle 2: Descriptive statistics of main indicators.

\begin{tabular}{|c|c|c|c|c|c|}
\hline Variables & $N$ & Mean & SD & Min & Max \\
\hline lntra & 1,404 & 13.900 & 2.314 & 2.773 & 18.580 \\
\hline $\operatorname{lncm}$ & 1,404 & 8.844 & 2.984 & 0.095 & 15.260 \\
\hline $\mathrm{sec}$ & 1,404 & 45.310 & 10.870 & 14.950 & 82.280 \\
\hline $\operatorname{lnrf}$ & 1,404 & 9.716 & 1.915 & 1.792 & 13.560 \\
\hline $\operatorname{lngdp}$ & 1,404 & 16.510 & 1.219 & 12.670 & 19.600 \\
\hline lnpop & 1,404 & 6.066 & 0.690 & 3.884 & 7.297 \\
\hline $\mathrm{pd}$ & 1,404 & 0.049 & 0.037 & 0.002 & 0.271 \\
\hline esis & 1,404 & 0.078 & 0.088 & 0.008 & 0.958 \\
\hline lntea & 1,404 & 8.493 & 1.385 & 2.773 & 11.160 \\
\hline proad & 1,404 & 5.826 & 6.403 & 0.049 & 64.000 \\
\hline lnta & 1,404 & 0.903 & 0.742 & 0.044 & 4.633 \\
\hline gov & 1,404 & 1.974 & 1.144 & 0.649 & 12.400 \\
\hline
\end{tabular}

TABLE 3: RMSPE comparison chart.

Objects

The predictive quality of the application of SCM before the implementation of the policy

Cargo flow at Xinzheng Airport RMSPE $\operatorname{lncm}$ (2001) $\operatorname{lncm}$ (2006) gov lnta lnpop pd esis sec lntea proad

$\begin{array}{lllllllllll}0.0931 & 9.85 & 10.84 & 1.13 & 1.49 & 6.62 & 0.10 & 0.07 & 53.45 & 10.05 & 3.40\end{array}$

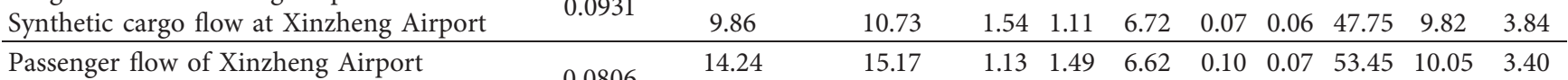

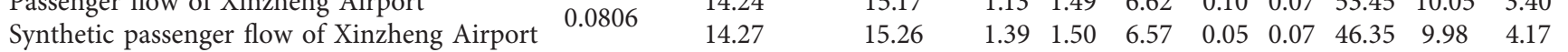

Table 4: Synthesized regional weight of development indicators of Xinzheng Airport.

\begin{tabular}{|c|c|c|c|c|}
\hline Subjects affected by preferential policies & \multicolumn{4}{|c|}{ Synthesized area (weight) } \\
\hline \multirow{2}{*}{ Cargo flow at Xinzheng Airport } & Nanchang & 0.287 & Chengdu & 0.562 \\
\hline & Luoyang & 0.057 & Ganzhou & 0.095 \\
\hline \multirow{3}{*}{ Passenger flow of Xinzheng Airport } & Nanchang & 0.032 & Harbin & 0.186 \\
\hline & Wuhan & 0.158 & Luoyang & 0.082 \\
\hline & Changsha & 0.543 & & \\
\hline
\end{tabular}

between Xinzheng Airport and other airports is relatively small. However, after the policy, the difference in the standard change degree of cargo traffic volume between Xinzheng Airport and other airports is gradually increasing. The cargo volume distribution curve of Xinzheng Airport is located outside other airports, which proves the effectiveness of the preferential policy effect. If given random disposal, there is a $1 / 25$ or $4 \%$ probability that a similar degree of variation between a certain airport and its synthetic airport in cargo throughput will appear. Therefore, the effect of 


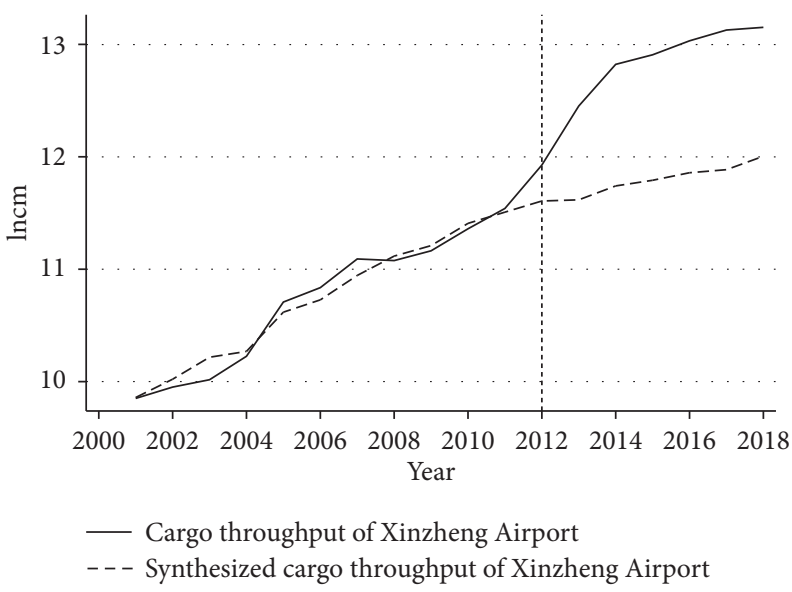

(a)

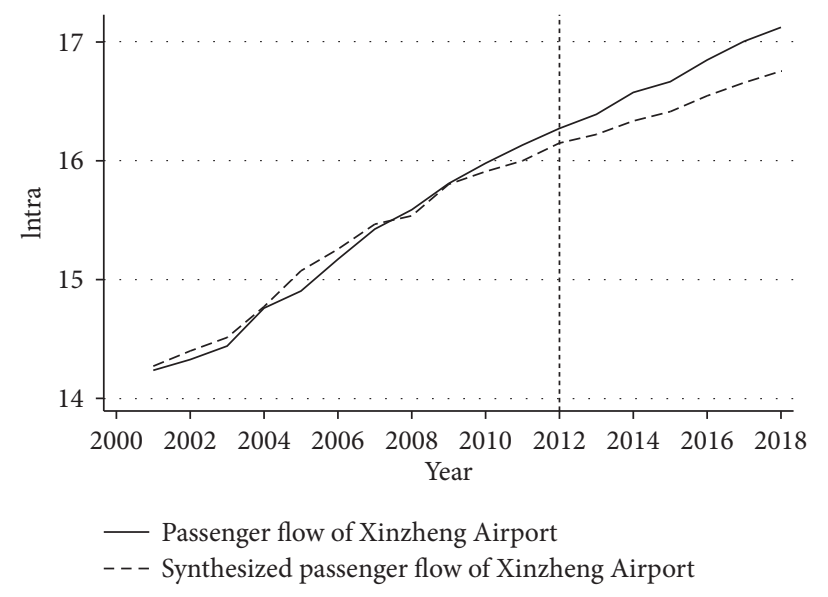

(b)

Figure 1: Cargo and passenger flow of Xinzheng Airport and its synthetic control objects.

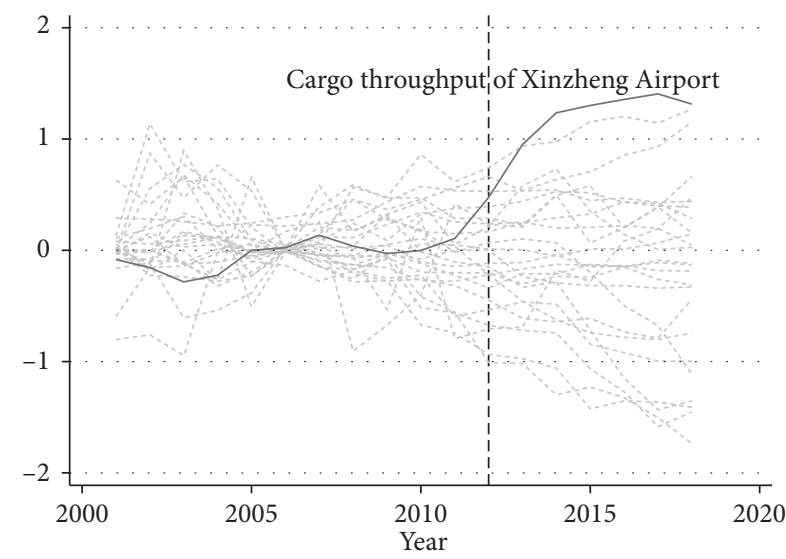

(a)

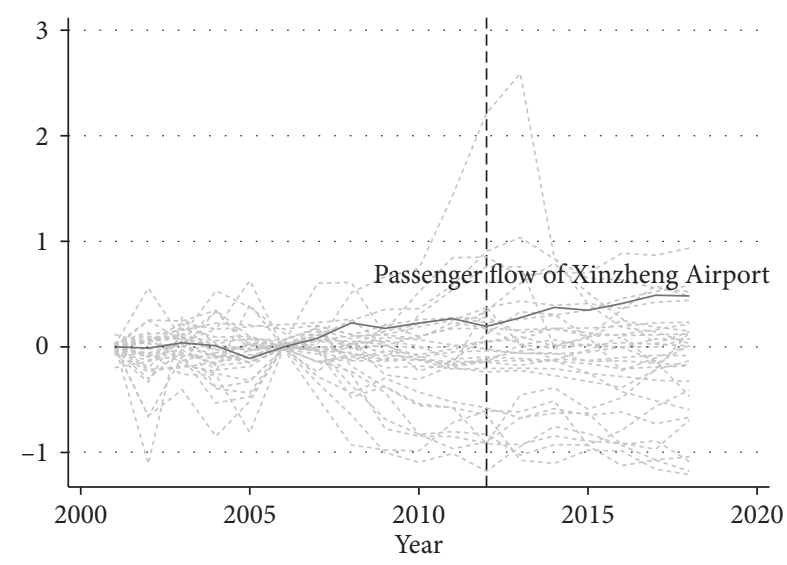

(b)

Figure 2: Distribution map of standard change degree of passenger and cargo flow at Xinzheng Airport and other airports.

preferential policies on airport cargo traffic is significant at the level of $4 \%$.

However, in Figure 2, after the implementation of the policy, the gap between Xinzheng Airport and other airports in the standard change of passenger flow has not increased significantly, and its distribution curve is in the interior of other airports, indicating that the policy effect of preferential policy on the passenger throughput of Xinzheng Airport is not significant. This reflects that the transport cost reduction effect, which is brought about by the preferential policy, may only be effective for airport cargo traffic, and passengers will not significantly increase the number of plane trips because of lower ticket prices. However, whether the preferential policy is ineffective to the airport passenger throughput still needs to be further tested.

4.1.2. Robustness Test. To avoid the deviation of the ranking test results due to the lack of randomness, we further utilize the falsification test method to inspect the robustness. The principle is that if the airport without preferential policy is selected for analysis, the passenger and cargo throughput of the airport is similar to that of Xinzheng Airport before the implementation of the policy, and there is a great difference between the real value and the composite value after the implementation of the policy; it shows that the result of the previous policy effect analysis is not robust. Otherwise, the analysis results of this paper are credible.

Considering two extreme cases, we construct airports with the largest weight and zero weight in the synthetic experiment objects. The largest weight indicates that the airport is most similar to the experimental subject, and a weight of zero indicates that the two are quite different. The robustness test results of the cargo and passenger throughput indicators of Xinzheng Airport are shown in Figures 3and 4. From Figure 3, it can be found that the difference between the actual observation value and the composite value of the false experimental objects of Xinzheng Airport cargo throughput index, Chengdu and Xi'an, does not show a trend similar to Xinzheng Airport cargo throughput after 2012. However, in Figure 4, the 


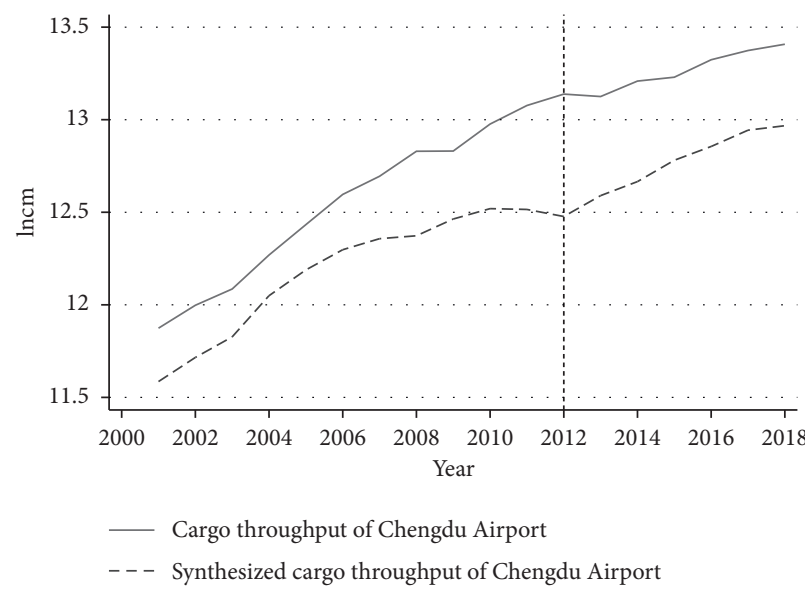

(a)

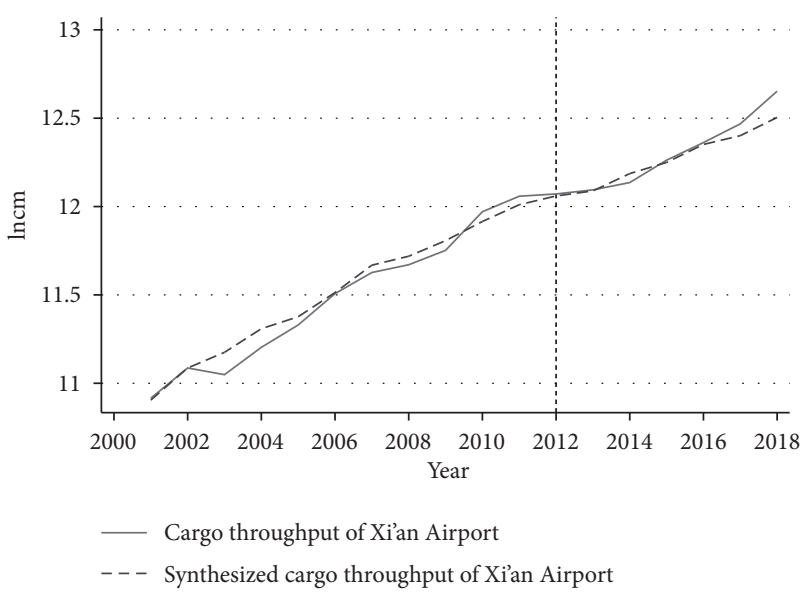

(b)

Figure 3: False experiment of cargo throughput at Xinzheng Airport. (a) The maximum weight and (b) the area with zero weight.

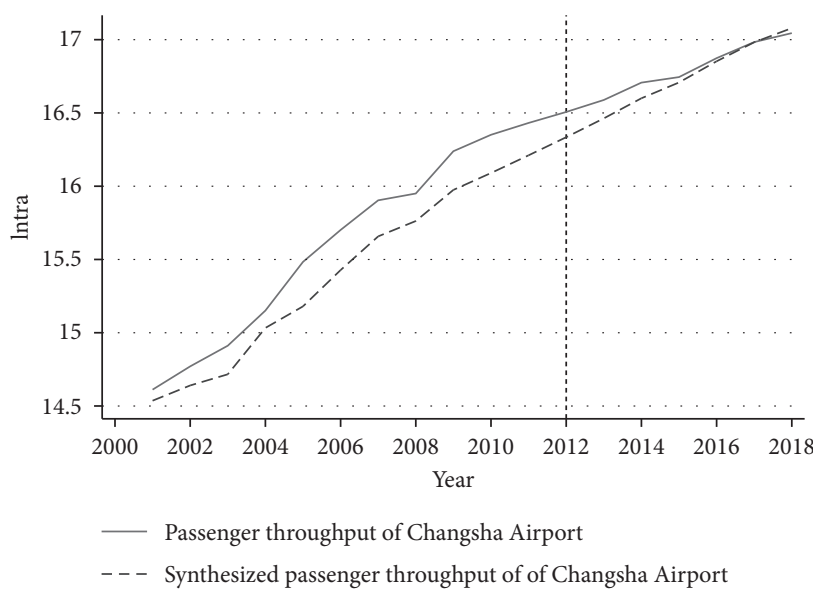

(a)

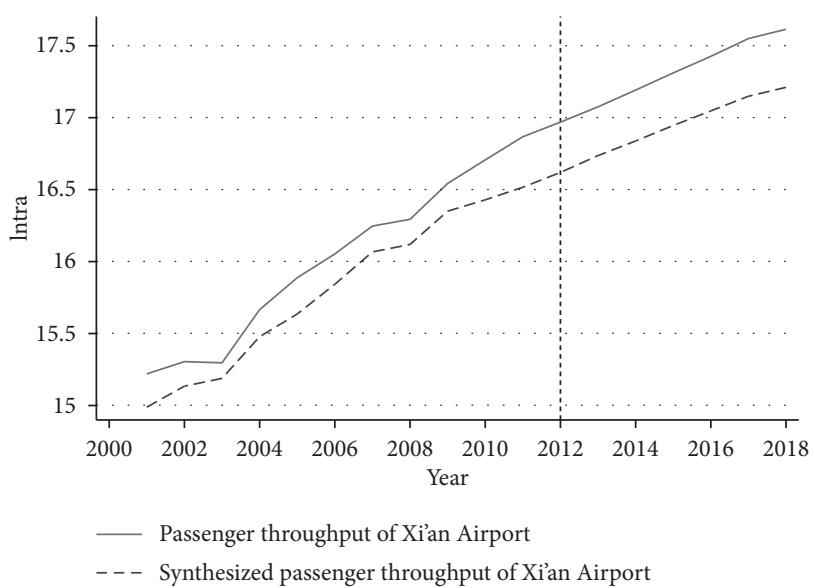

(b)

FIgURe 4: False experiment of passenger throughput at Xinzheng Airport. (a) The maximum weight and (b) the area with zero weight.

variation trend of the false experimental group of Xinzheng Airport passenger flow, Changsha and Xi'an, is similar to that of Xinzheng Airport, which is consistent with the conclusion of the ranking test, and further illustrates that the preferential policy only had an impact on the cargo transportation volume of the experimental airport. The reason for this phenomenon is easy to explain. First, the industry transferred from the airport in eastern China to the central and western is cargo transportation; compared with passenger transport, freight transportation can better improve the regional industrial structure and promote economic development. Secondly, since the airport ownership reform in 2001, the contribution rate of air cargo transport has exceeded that of passenger transport [46]. Air cargo transport has become the engine of regional economic growth.

Since then, the research results of SCM showed that preferential policies have a positive impact on the development of airports, especially on cargo transportation. $\mathrm{H}_{2}$ is proved to be correct.
4.2. The Empirical Results of the Spatial Econometric Model. The above content has verified that the preferential behavior of the government will increase the cargo volume at the local airport. Furthermore, we will analyze the spatial spillover effect of airport freight volume through the SDM. If there is a strong siphon relationship in cargo flow between airports, then the implementation of preferential policies will intensify this competition.

Based on the research purpose of this paper, we conduct a subsample study on the airports in the eastern, central, and western of China. However, the coefficient of independent variable in the SDM model does not represent the elastic coefficient, so direct, spatial spillover, and total effect need to be calculated. The results are presented in Table 5. For brevity, the result reports only the variables we care about.

From the direct effects in Table 5, it can be concluded that, overall, the cargo throughput and passenger throughput of China's airports have a positive impact on the local economy. However, the impact of flight takeoffs and 
TABLE 5: Direct, indirect, and total effects of the SDM.

\begin{tabular}{|c|c|c|c|c|}
\hline Spatial effect & Area & lntra & $\operatorname{lncm}$ & $\ln r f$ \\
\hline \multirow{3}{*}{ Direct effect } & The whole country & $\begin{array}{c}0.0292^{* * *} \\
(-3.34)\end{array}$ & $\begin{array}{c}0.0224^{* * *} \\
(-4.38)\end{array}$ & $\begin{array}{c}-0.0235^{* * *} \\
(-3.22)\end{array}$ \\
\hline & Eastern region & $\begin{array}{c}0.0157^{*} \\
(-1.7)\end{array}$ & $\begin{array}{c}0.0113^{*} \\
(-1.83)\end{array}$ & $\begin{array}{l}0.0135 \\
(-1.53)\end{array}$ \\
\hline & Central and western & $\begin{array}{c}0.0571^{* * *} \\
(-3.77)\end{array}$ & $\begin{array}{c}0.007 \\
(-0.85)\end{array}$ & $\begin{array}{c}-0.0579^{* * *} \\
(-5.07)\end{array}$ \\
\hline \multirow{3}{*}{ Indirect effect/spatial spillover effect } & The whole country & $\begin{array}{l}0.0318 \\
(-1.26)\end{array}$ & $\begin{array}{c}-0.0059 \\
(-0.41)\end{array}$ & $\begin{array}{l}-0.025 \\
(-1.07)\end{array}$ \\
\hline & Eastern region & $\begin{array}{l}0.0176 \\
(-1.07)\end{array}$ & $\begin{array}{l}0.0092 \\
(-0.65)\end{array}$ & $\begin{array}{c}0.0001 \\
(0.00)\end{array}$ \\
\hline & Central and western & $\begin{array}{c}0.1356^{* *} \\
(-2.35)\end{array}$ & $\begin{array}{c}-0.0685^{* * *} \\
(-2.93)\end{array}$ & $\begin{array}{c}-0.1131^{*} \\
(-1.90)\end{array}$ \\
\hline \multirow{3}{*}{ Total effect } & The whole country & $\begin{array}{c}0.0610^{* *} \\
(-2.12)\end{array}$ & $\begin{array}{c}0.0165 \\
(-0.97)\end{array}$ & $\begin{array}{c}-0.0485^{*} \\
(-1.81)\end{array}$ \\
\hline & Eastern region & $\begin{array}{c}0.0333^{*} \\
(-1.65)\end{array}$ & $\begin{array}{l}0.0206 \\
(-1.16)\end{array}$ & $\begin{array}{c}0.0136 \\
(-0.65)\end{array}$ \\
\hline & Central and western & $\begin{array}{c}0.1927^{* * *} \\
(-3.09)\end{array}$ & $\begin{array}{c}-0.0615^{* *} \\
(-2.27)\end{array}$ & $\begin{array}{c}-0.1710^{* * *} \\
(-2.63)\end{array}$ \\
\hline
\end{tabular}

$t$ statistics in parentheses. ${ }^{*} p<0.1,{ }^{* *} p<0.05$, and ${ }^{* * *} p<0.01$.

landings on the regional economy is significantly negative. To a certain extent, aircraft takeoffs and landings reflect the strength of government support to airports; from the negative impact of the increase in aircraft takeoffs and landings at the airport on the regional economy, it can be inferred that these preferential policies may also induce airlines to use large aircraft and increase the number of flights to obtain high subsidy standards, regardless of low occupancy rates, which are equivalent to using financial subsidies to make up for the problem of inefficient operation. It increases the burden of regional finance and hinders economic growth. In the subsample estimation, the passenger and cargo throughput of the eastern airport plays a significant role in promoting the regional economy. However, in the central and western regions, only the airport passenger flow has a significant promoting effect on the regional economy, while the cargo traffic volume has no obvious pulling effect on the regional economy. It is preliminarily inferred that the eastern region is the Chinese economic center and high-end manufacturing area, so the demand for air transport in the eastern region is very large, which can significantly promote regional economic growth, while the high-end manufacturing industry in the central and western regions is underdeveloped, and the freight volume is slightly inadequate. As a result, its pulling effect on the economy is not obvious.

From the decomposition of spatial spillover effects, it can be found that the spatial spillover effects of various indicators of airports, in the whole country and the eastern region, are not significant, which may be because the development of the eastern airport has entered a mature period, the route network layout and market division have been completed, and the competitive relationship has been transformed into a cooperative relationship, which leads to the fact that the spatial spillover effect of an airport on other airports around is weak. In contrast, the central and western regions of China are vast and have yet to complete their route network layout; airports in each region already have made different efforts to grab market share. The economic spillover effect of passenger flow from airports in the central and western on surrounding areas is significantly positive. But, the spatial spillover effect of cargo traffic in the central and western airports, which we are concerned about, is significantly negative, indicating that the airports in the central and western regions are still in a state of fierce competition in cargo.

From the total effect of Table 5, we can summarize that the overall spatial spillover effect of airport cargo traffic in China is significantly negative, which shows that the competition of local airports in freight transport did not promote the development of the local economy. On the contrary, the overall economic income is negative due to disorderly vicious competition.

The result of the spatial econometric model is closely related to the selection of the weight matrix. Drawing on related research experience $[32,34,37]$, we select the $0-1$ matrix, based on the $800 \mathrm{~km}$ distance threshold, and the matrix, based on the reciprocal of geographical distance, to study the spatial spillover effect of the airport again. The results are consistent with the previous studies, so the empirical results of the SDM are robust. The rationality of $\mathrm{H}_{3}$ has been proved, and the cargo throughput of airports in central and western China shows a siphon effect.

4.3. Discussion Combined with the Results of the SCM and $S D M$. From the previous analysis of the SCM, it is concluded that the preferential policy implemented by Zhengzhou to the aviation economic zone is finally reflected in the increase of airport cargo (hypothesis 2), which shows that the current competition focus on airports in central and western China lies in cargo volume. Furthermore, the research results of SDM show that the spatial spillover indirect 
effect of airport cargo transportation in central and western China is negative ((hypothesis 3), and there is a significant siphon effect between airports in central and western China. It indicates that the implementation of preferential policies in one area will increase the cargo throughput of the local airport but will correspondingly take goods from other areas. To offset this impact, other regions have also introduced policies to reduce the cost of transportation at local airports.

Taking Xian as an example, according to incomplete statistics, the total amount of foreign trade import and export air cargo, which is diverted by other provinces in Xi'an every year, amounts to 15000 tons, accounting for $40 \%$ of the stock of international air logistics in Xi'an. To recover this part of the lost goods, Xi'an issued the Support Measures for Accelerating the Development of General Aviation Industry and the Incentive Measures for Investment and Tax Introduction of Xi'an National Civil Aerospace Industry Base in July 2019. The preferential treatment, given to airports in terms of attracting investment and operation, far exceeds that of other central and western regions. In the process of the transfer of eastern airports to the central and western regions, such a policy is undoubtedly very attractive, so aerospace companies are likely to choose these places with more preferential policies. At the same time, Xi'an, Chengdu, Zhengzhou, and Wuhan, which belong to the mutual radiation circle, have a competition in aviation resources. If a place heavily subsidizes the air routes, it will seize the freight resources that originally belong to other regions. To avoid the local aviation industry that was excessively squeezed, other regions will inevitably adopt corresponding preferential policies to offset the impact of the existing preferential policies. The production cost of each airport has been temporarily reduced, the cargo volume has increased, and the cost of goods originally taken by land has also been reduced to acceptable air transport. But overall, the cost of air cargo in the central and western regions is on the rise. Obviously, it is not conducive to the sustainable development of the region and the air transport industry. This can explain why the increase in cargo throughput at airports in central and western China has a negative impact on the economy.

Since then, $\mathrm{H}_{1}$ has been proved, the implementation of preferential policies has accelerated the convergent competition in the construction of aviation hubs in the central and western regions and adversely affected the development of the regional economy.

4.4. The Working Mechanism of Preferential Policies. The airports can accelerate the flow of labor capital between regions and promote the upgrading of industrial structure and regional economic transformation $[26,28]$. Therefore, we will test the working mechanism of preferential policy from two aspects of human capital and industrial structure. The model is as follows:

$$
\begin{aligned}
Y_{\mathrm{it}} & =\alpha_{1}+\beta_{i} D \times \theta_{i}+\delta_{i} X_{i}+\mu_{i}+\nu_{t}+\varepsilon_{\mathrm{it}}, \\
D & =d_{i} \times d_{t} .
\end{aligned}
$$

Here, $Y$ is the regional economic level, $\alpha_{1}$ is the constant, policy effect $(D)$ is the interactive term of the time virtual variable $d_{t}(1$ after 2011 , otherwise 0$)$ and the regional virtual variable $d_{i}$ (preferential areas take 1 , otherwise 0$)$, and $\theta$ is the coefficient of the interaction term of the core explanatory variable (human capital, industrial structure). In this paper, the interaction term of policy effect $D$ and the two variables is used to test the mechanism of policy action. $X$ is a series of control variables, such as airport cargo flow, passenger flow, takeoff and landing times, and government intervention. Besides, the model controls the regional effect and time effect. The test results are shown in Table 6.

The first column does not include interaction terms, which is treated as a comparison. In the second column, the estimated results of policy effect and human capital are both significantly positive, and the implementation of policies can promote regional economic development by improving human capital. The interaction term of the two variables is significantly negative. With the improvement of regional human capital, the promotion effect of preferential policies on the regional economy is increasingly weak. Similarly, in the third column, industrial structure has a positive impact on the regional economy, but the interaction term between policy effect and industrial structure is negative, indicating that preferential policies can hardly play a good effect on the improvement of industrial structure. This result is consistent with the conclusion of existing studies. Preferential policies can play a good supporting role in areas with poor human capital and industrial level. To some extent, this confirms the motivation of the central and western regional governments to adopt preferential policies for airports. However, with the development of the economy and society, the promoting role of preferential policies on the economy gradually decreases and such measures may not achieve the desired results [11].

\section{Further Discussion on the Causes of the Preferential System}

The rapid growth of China's economy is inseparable from the rapid growth of airports in various regions. However, under the interactive influence of multiple factors, such as the rise in the price of factors of production in the eastern coastal areas, the continuous appreciation of the RMB exchange rate, the reduction of the proportion of export tax rebates, and the tightening of trade policies, the cost of airport operation in these areas remains high, and the restrictions on resources and environment are becoming more and more significant, so the cargo transport activities at the eastern airport began to shift to the central and western. In recent years, many aviation hub cities in China have proposed the concept of building airport economic zones or aviation metropolises. As the factor-intensive economies move from the east to the west, China has positioned Zhengzhou, Wuhan, Xi'an, and other cities as vital logistics hubs in the country. Among them, the goal of Xinzheng Airport in Zhengzhou is to become an international aviation logistics center, while Wuhan Airport proposed the development task of building an airport economic zone to catch up with Beijing, Shanghai, and Guangzhou, while Xi'an and other places are positively influenced by Belt and Road Initiative and strongly supported by the local government. 
TABLE 6: The mechanism test of preferential policy.

\begin{tabular}{|c|c|c|c|}
\hline & $(1)$ & (2) & (3) \\
\hline $\mathrm{D}$ & $\begin{array}{c}0.0651^{*} \\
(1.90)\end{array}$ & $\begin{array}{c}10.3513^{* * *} \\
\quad(9.29)\end{array}$ & $\begin{array}{c}1.1473^{* * *} \\
\quad(9.12)\end{array}$ \\
\hline $\operatorname{lntra}$ & $\begin{array}{c}0.0283 \\
(1.47)\end{array}$ & $\begin{array}{c}0.0284 \\
(1.47)\end{array}$ & $\begin{array}{c}0.0288 \\
(1.49)\end{array}$ \\
\hline $\operatorname{lncm}$ & $\begin{array}{c}0.0232 \\
(1.35)\end{array}$ & $\begin{array}{c}0.0232 \\
(1.35)\end{array}$ & $\begin{array}{c}0.0227 \\
(1.32)\end{array}$ \\
\hline $\ln r f$ & $\begin{array}{c}-0.0256 \\
(-1.51)\end{array}$ & $\begin{array}{c}-0.0256 \\
(-1.51)\end{array}$ & $\begin{array}{c}-0.0256 \\
(-1.51)\end{array}$ \\
\hline gov & $\begin{array}{c}-0.0436^{* * *} \\
(-2.90)\end{array}$ & $\begin{array}{c}-0.0436^{* * *} \\
(-2.90)\end{array}$ & $\begin{array}{c}-0.0435^{* * *} \\
(-2.89)\end{array}$ \\
\hline lnta & $\begin{array}{c}0.0839^{* * *} \\
(2.74)\end{array}$ & $\begin{array}{c}0.0839^{* * *} \\
(2.74)\end{array}$ & $\begin{array}{c}0.0842^{* * *} \\
(2.74)\end{array}$ \\
\hline $\operatorname{lnpop}$ & $\begin{array}{c}0.4652^{* * * *} \\
(3.82)\end{array}$ & $\begin{array}{c}0.4664^{* * *} \\
(3.83)\end{array}$ & $\begin{array}{c}0.4749^{* * *} \\
\quad(3.92)\end{array}$ \\
\hline $\mathrm{pd}$ & $\begin{array}{r}0.1787 \\
(0.19)\end{array}$ & $\begin{array}{l}0.1891 \\
(0.20)\end{array}$ & $\begin{array}{c}0.2546 \\
(0.28)\end{array}$ \\
\hline esis & $\begin{array}{c}-0.0976 \\
(-0.35)\end{array}$ & $\begin{array}{c}-0.1002 \\
(-0.36)\end{array}$ & $\begin{array}{c}-0.1179 \\
(-0.42)\end{array}$ \\
\hline $\sec$ & $\begin{array}{c}0.0118^{* * *} \\
(5.13)\end{array}$ & $\begin{array}{c}0.0118^{* * *} \\
(5.14)\end{array}$ & $\begin{array}{c}0.0119^{* * *} \\
\quad(5.19)\end{array}$ \\
\hline lntea & $\begin{array}{c}0.0546 \\
(1.56)\end{array}$ & $\begin{array}{c}0.0549 \\
(1.58)\end{array}$ & $\begin{array}{c}0.0547 \\
(1.57)\end{array}$ \\
\hline proad & $\begin{array}{c}0.0045 \\
(1.09)\end{array}$ & $\begin{array}{c}0.0045 \\
(1.09)\end{array}$ & $\begin{array}{c}0.0045 \\
(1.09)\end{array}$ \\
\hline Dxlntea & & $\begin{array}{c}-0.9480^{* * *} \\
(-9.17)\end{array}$ & \\
\hline Dxsec & & & $\begin{array}{c}-0.0221^{* * *} \\
(-8.56)\end{array}$ \\
\hline Provincial effect & Yes & Yes & Yes \\
\hline Time effect & Yes & Yes & Yes \\
\hline _cons & $\begin{array}{c}11.1517^{* * *} \\
(14.52)\end{array}$ & $\begin{array}{c}11.1411^{* * *} \\
(14.52)\end{array}$ & $\begin{array}{c}11.0849^{* * *} \\
(14.47)\end{array}$ \\
\hline$R^{2}$ & 0.971 & 0.971 & 0.971 \\
\hline$N$ & 1404 & 1404 & 1404 \\
\hline
\end{tabular}

Thus, the impact of the airport economy is not limited to industrial development; spatial planning is imperative.

The practice of China's aviation economic zone construction has surpassed related theoretical research in time, and the air economic zone in the central and western has unknowingly entered the fiery construction stage. In 2013, the State Council of China approved the Development Plan of Zhengzhou Airport Economic Comprehensive Experimental Zone (2013-2025), and the construction of Zhengzhou Airport has become a national development strategy. After that, the Civil Aviation Administration of China approved the Development Plan of Xi'an Aviation City Experimental Zone (2013-2025). Xi'an strives to build the Silk Road aviation hub. Wuhan Aviation Economic Zone covers an area of about 1000 square kilometers, relying on the advantages of transportation, industry, and talents, and it has put forward the goal of building a modern waterfront aviation city. Also, Chongqing Jiangbei International Airport has put forward an overall plan for the construction of an airport metropolitan area, and the Shuangliu area in Chengdu strives to build a modern airport new city. Changsha Airport Economic Zone was approved in 2017, to build a green, ecological, and smart aviation city. From the development goals and overall strategy of the airport economic zones in the central and western, we can see that the goal of these airport economic zones is to build a modern aviation city.

Based on the above content, we can understand the differences in the degree of subsidies to the aviation economy, which was implemented by the provincial and municipal governments in China in terms of time and space.

First, the preferential system has an outstanding policy effect. In the initial period of the industry, if enterprises follow the rules, many processes may encounter obstacles. However, a small number of enterprises had received support from the government in the process of development, and then they could overcome the obstacles of the system to the enterprises, rapidly accumulate development strength in a short time, and gradually form the pillar of the regional economy with market competitiveness. For this reason, in the initial stage of airport construction, it is feasible for the government to give it policy support to help it tide over the difficult times.

With the rapid development of China's economy, the original economic operation mode and industrial linkages need to be reintegrated, while the airport economy has improved the efficiency of the use of information, knowledge, capital, and technology and reorganized the traditional mode of production in the aspects of passenger flow, logistics, and information flow, which plays a prominent role in improving the timeliness and added value of products. Therefore, the airport economy is not a separate economic region of each province and city, but a concentrated embodiment of the overall local economic development level. Almost all regions attach great importance to the construction speed, convenience, intelligence, and coordination of the airport economy. The tradition of supporting airport policy has not disappeared but has become more obvious and intensive.

Second, the development level of the airport economy in the central and western is close. Most of the airport economic zones in the central and western regions of China already have mature plans. According to the report of China Airport Economic Development Index (2019), the top 10 hub driving indices of the 36 airport economic zones, which are under construction and planned by the end of 2018, are Shanghai, Beijing, Guangzhou, Chengdu, Wuhan, Shenzhen, Zhengzhou, Chongqing, Hangzhou, and Kunming. Cities in the central and western account for half of them. In the central and western, Chengdu, Chongqing, and Zhengzhou are among the top three in the overall index, while the total index levels of other provincial capitals are also very close to them. For airports in the central and western regions, the earliest ones to receive relevant policy supports from the local governments will be more competitive. Therefore, the relatively close level of development, as well as local attention to the airport economy, has become one of the important reasons for the continuous strengthening of the preferential system.

Currently, for gaining more flights and becoming a major regional aviation hub, key cities in the central and western have issued flight subsidy policies. The result will be 
three effects. First, the resources obtained by the airport are too concentrated, which is relatively not conducive to the development of other industries and resulting in a crowdingout effect. Second, the preferential model will produce a certain degree of dependence, making specific industries wait for the arrival of local protection or preferential conditions, but cannot involve in the larger-scale market competition, affecting the long-term development of the industry. Third, on the one hand, this measure will increase the financial burden of the city, which is not conducive to the healthy development of the regional economy. On the other hand, the preferential policy will not make the region have a better space for development; on the contrary, it will increase the vicious competition of the airport economy. To cope with the flight subsidies of neighboring provinces and cities, all localities must constantly increase their preferential conditions. Owing to the fact that the preferential system cannot bring the expected high income and forms the resource distortion, it will produce a result, which is contrary to the initial desire of the implementation of the preferential system, and finally affect the development of the regional economy. All these indicate the aviation hub dispute trend towards more intense competition.

\section{Main Conclusions and Policy Recommendations}

At present, the governments of the central and western regions have issued policies to vigorously develop aviation hubs, but it may lead to repeated construction and convergent competition. We collected sample data from 78 airports of Chinese mainland from 2001 to 2018. By using the SCM, we found that the preferential policy had a positive effect on airport cargo traffic, and the results passed the robustness test. Furthermore, we used SDM to study the spatial spillover effect of airports. The results show that the spatial spillover effect of airport cargo traffic in central and western China is significantly negative, and there is fierce competition in cargo transport among airports. The implementation of preferential policies has intensified this competition and further led to the growth of cargo transport volume which harms the regional economy. At the same time, the results of mechanism analysis show that the airport has a greater role in promoting the economy in areas with insufficient human capital and industrial development, which also proves the motivation of the central and western regions to carry out competitive subsidies for airports. Judging from the current situation, the preferential policy in the aviation economy will accelerate the vicious competition in the aviation economic zones in the central and western regions, which is not conducive to the optimization, upgrading, transformation, and development of the regional economic structure in the long run. At the same time, after more than ten years of construction and accumulation, the national airport economic zone has entered a stage of deep development. As a new economic form and an important part of the regional economy, blindly giving preferential treatment to it is likely to disturb the market order.
Based on the above conclusions, we put forward the following policy recommendations.

First, the GDP championship system needs to be improved. The GDP tournament system is the direct reason for the formation of the preferential system. To improve it, it is necessary to improve the promotion system of government officials. The country cannot merely take the growth of GDP as the only political achievement nor judge the economic development of the provinces simply by the level of GDP. Second, the policies for large multinational enterprises must be transparent. The aviation preferential policies of various regions for large multinational enterprises need to be announced to the public, so as to reduce regional unfair competition and prevent foreign enterprises from obtaining unfair subsidies in China, which will reduce the negative impact on the national economy and promote fair competition. Third, the Civil Aviation Administration of China has better continued to deepen the market-oriented reform of civil aviation domestic freight rates, strengthen the market price determination mechanism, and gradually liberalize the passenger transport prices and cargo transport prices of more routes in order to finally realize the transportation price determined by market competition. Fourth, multiple airports need to form a regional consultative mechanism for subsidy policies. There is no real winner in the price war, and the central and western regions need to realize the harm of malicious competition; according to the characteristics and advantages of the local economy, they need to formulate the key development path of the aviation economy, take the path of differentiation, and form a transparent and efficient regional consultation mechanism. Particularly, the release of local subsidy policies is the best to fully communicate with the surrounding airports in advance.

\section{Data Availability}

The data selected in this paper are mainly from Civil Aviation from the Perspective of Statistics (2001-2018), China Urban Statistical Yearbook (2002-2019), and the annual Statistical Bulletin of Civil Aviation Airport Production. Some of the missing values are made up by consulting the National Economic Development Bulletin and the website of the Bureau of Statistics.

\section{Disclosure}

Chengyu Li and Guangliang Zhou are co-first authors.

\section{Conflicts of Interest}

The authors declare that they have no known competing financial interests or personal relationships that could have appeared to influence the work reported in this study.

\section{Authors' Contributions}

Chengyu Li and Guangliang Zhou contributed equally to the work. 


\section{Acknowledgments}

This work was supported by the National Natural Science Foundation of China (71803181), National Social Science Foundation of China (19FGLB062), Science and Technology Innovative Talents Program of Henan (Humanities and Social Sciences) (2021-CX-019), Philosophy and Social Science Program of Henan (2020BJJ067 and 2020JC17), and Key Project of Philosophy and Social Science Research in Colleges and Universities of Henan (2019-YYZD-18 and 2021-JCZD-25).

\section{References}

[1] A. Mačiulis, A. V. Vasiliauskas, and G. Jakubauskas, "The impact of transport on the competitiveness of national economy," Transport, vol. 24, no. 2, pp. 93-99, 2009.

[2] S. J. Appold and J. D. Kasarda, "The airport city phenomenon evidence from large US airports," Urban Studies, vol. 50, no. 6, pp. 1239-1259, 2013.

[3] S. J. Appold, "Airport cities and metropolitan labor markets an extension and response to Cidell," Journal of Economic Geography, vol. 15, no. 6, pp. 1145-1168, 2015.

[4] E. Heymann, A. Karollus, L. Slomka, D. B. AG, and R. Hoffmann, Germany's Regional Airports Under Political And Economic Pressure, pp. 1-15, Deutsche Bank Research, Frankfurt, Germany, 2015.

[5] K. Button and S. Taylor, "International air transportation and economic development," Journal of Air Transport Management, vol. 6, no. 4, pp. 209-222, 2000.

[6] N. Sheard, "Airports and urban sectoral employment," Journal of Urban Economics, vol. 80, no. 3, pp. 133-152, 2014.

[7] J. Cidell, "The role of major infrastructure in subregional economic development an empirical study of airports and cities," Journal of Economic Geography, vol. 15, no. 6, pp. 1125-1144, 2015.

[8] E. L. F. A. Association, Liberalisation of European Air Transport The Benefits of Low Fares Airlines to Consumers, Airports, Regions and the Environment, pp. 13-16, European Low Fares Airlines Association, Brussels, Belgium, 2004.

[9] P. Breidenbach, "Ready for take-off? The economic effects of regional airport expansions in Germany," Regional Studies, vol. 54, no. 8, pp. 1084-1097, 2020.

[10] L. Zhou, "Governing China's local officials an analysis of promotion tournament model," Economic Research Journal, vol. 7, pp. 36-50, 2007.

[11] C. E. Bai, "The preferential mode is not sustainable," Money China, vol. 1, pp. 56-58, 2015.

[12] J. Zhang, "Decentralization and growth China context," China Economic Quarterly, vol. 1, pp. 21-52, 2008.

[13] X. Y. Fan, "The calculation of the rate of return on industrial capital in China and the analysis of regional and industry structure," The Journal of World Economy, vol. 5, pp. 48-57, 2004.

[14] Y. Y. Jiang and R. E. Ren, "The rate of return of industrial capital in China," China Economic Quarterly, vol. 3, pp. 877-888, 2004.

[15] T. Shao and J. K. Li, "Distorted capital market, rate of return on capital and differences in ownership," Economic Science, vol. 5, pp. 35-45, 2010.

[16] T. Shao, "Financial mismatch, ownership structure and return on capital a case of industrial enterprises in China from 1999 to 2007," Journal of Financial Research, pp. 51-68, 2010.
[17] C. E. Bai and L. Ma, "Government intervention, optimal taxation and structural adjustment," Taxation Research, vol. 6, pp. 46-50, 2015.

[18] C. E. Bai, Z. J. Qian, and K. P. Wu, "Determinants of factor shares in China's industrial sector," Economic Research Journal, vol. 8, pp. 16-28, 2008.

[19] C. E. Bai and Z. J. Qian, "Factor income share in China the story behind the statistics," Economic Research Journal, vol. 44, no. 3, pp. 27-41, 2009.

[20] Y. C. Cao, Y. R. Xi, and W. W. Li, "Analysis on the formation of airport economy from the perspective of new economic geography," Inquiry Into Economic Issues, vol. 2, pp. 49-54, 2009.

[21] C. Fershtman, "The interdependence between ownership status and market structure the case of privatization," Economica, vol. 57, no. 227, pp. 319-328, 1990.

[22] H. Cremer, M. Marchand, and J.-F. Thisse, "Mixed oligopoly with differentiated products," International Journal of Industrial Organization, vol. 9, no. 1, pp. 43-53, 1991.

[23] W. C. Merrill and N. Schneider, "Government firms in oligopoly industries a short-run analysis," The Quarterly Journal of Economics, vol. 80, no. 3, pp. 400-412, 1966.

[24] M. D. Irwin and J. D. Kasarda, "Air passenger linkages and employment growth in U.S. Metropolitan areas," American Sociological Review, vol. 56, no. 4, pp. 524-537, 1991.

[25] J. K. Brueckner, "Airline traffic and urban economic development," Urban Studies, vol. 40, no. 8, pp. 1455-1469, 2003.

[26] W. Song and K. Yang, "The impacts of air transportation and airport on regional economic development," Scientia Geographica Sinica, vol. 6, pp. 649-657, 2006.

[27] X. Y. Yang, S. Y. Mao, and N. Zhang, "The analysis of the airport developments' contribution to regional tourism," Statistics \& Information Forum, vol. 26, no. 6, pp. 85-89, 2011.

[28] F. David and G. Saporito, The Impact of a New Airport on International Tourism The Case of Ragusa (Sicily), Bank of Italy, Economic Research and International Relations Area, Rome, Italy, 2017.

[29] D. Baker, R. Merkert, and M. Kamruzzaman, "Regional aviation and economic growth cointegration and causality analysis in Australia," Journal of Transport Geography, vol. 43, pp. 140-150, 2015.

[30] Y.-H. Lee, G.-U. Yu, and M.-S. Kim, "Economic spillover effects of airport investment on regional production," Journal of Korean Society of Transportation, vol. 23, no. 2, pp. 37-50, 2005.

[31] L. Zhang, W. Chen, Z. N. Song, and J. F. Xue, "Study on the relationship between airport operation and regional economic growth," Progress in Geography, vol. 29, no. 12, pp. 1570-1576, 2010.

[32] Q. L. Wang, "Research on the relationship between China's airport economic zone and the hinterland regional economy based on dynamic spatial model," Geographical Research, vol. 36, no. 11, pp. 2141-2155, 2017.

[33] N. B. Li, Research of the Airport Spacial Spillover Effect and its Regional Difference, Southeast University, Dhaka, Bangladesh, 2013.

[34] X. Chen, J. Yuan, and L. Dai, “Airport network spillover effect with spatial econometric models," Journal of Transportation Systems Engineering and Information Technology, vol. 19, no. 4, pp. 211-217, 2019.

[35] A. Abadie and J. Gardeazabal, "The economic costs of conflict a case study of the Basque Country," American Economic Review, vol. 93, no. 1, pp. 113-132, 2003.

[36] H. L. Zhang, J. C. Huang, F. Jia, and A. Han, "Research on the spatial spillover effect of economic development of 288 cities 
in China," Statistics \& Decision, vol. 35, no. 24, pp. 141-144, 2019.

[37] L. Gao, Research on Economic Spillover Effect of Airport Based on Spatial Econometric Model, pp. 13-16, Civil Aviation Flight University of China, Deyang, China, 2020.

[38] L. Zhang and W. Shi, "The evolution and driving mechanism of spatial structurein airport economic zone Taking Shanghai Hongqiao International Airport as an example," Geographical Research, vol. 33, no. 1, pp. 57-70, 2014.

[39] N. Baltaci, O. Sekmen, and G. Akbulut, "The relationship between air transport and economic growth in Turkey crossregional panel data analysis approach," Journal of Economics and Behavioral Studies, vol. 7, no. 1, pp. 89-100, 2015.

[40] M. Chen, Q. H. Gui, M. Lu, and Z. Chen, "How to maintain China's high growth rate via scale economy-an empirical study of economic opening and domestic market segmentation," China Economic Quarterly, vol. 1, pp. 125-150, 2008.

[41] Z. Y. Fan and J. Zhang, "Fiscal decentralization, intergovernmental transfer and market integration," Economic Research Journal, vol. 45, no. 3, pp. 53-64, 2010.

[42] B. B. Yu, "Economic growth effects of industrial restructuring and productivity improvement-analysis of dynamic spatial panel model with Chinese city data," China Industrial Economics, vol. 12, pp. 83-98, 2015.

[43] R. J. Duan, “Technological progress, technological efficiency and industrial structure upgrading-based on spatial econometric analysis of 285 cities in China," R\&D Management, vol. 30, no. 6, pp. 106-116, 2018.

[44] M. Percoco, "Airport activity and local development evidence from Italy,” Urban Studies, vol. 47, no. 11, pp. 2427-2443, 2010.

[45] A. Abadie, A. Diamond, and J. Hainmueller, "Synthetic control methods for comparative case studies estimating the effect of California's tobacco control program," Journal of the American Statistical Association, vol. 105, no. 490, pp. 493505, 2010.

[46] S. F. Sun and Y. J. Li, "An empirical analysis on influence of air transport development to chinese economic growth," in Proceedings of the 2011 International Conference on E-Business and E-Government (ICEE), pp. 1-4, Shangai, China, May 2011. 